\title{
Editorial: International Journal of Advanced Manufacturing: MATADOR special issue
}

\author{
Paul Mativenga ${ }^{1}$ \\ Published online: 28 April 2020 \\ (C) Springer-Verlag London Ltd., part of Springer Nature 2020
}

This special issue of the International Journal of Advanced Manufacturing Technology - MATADOR, contains original papers, sifted by rigorous journal peer review, and contributed by researchers from many countries and continents. These papers arise from the 40th International MATADOR Conference on advanced manufacturing held in Hangzhou, China, on 8-10 July 2019. The MATADOR series of conferences covers the topics of Manufacturing, Automation and Systems, Technology, Applications, Design, Organization and Management, and Research. The MATADOR Conference was established in 1959, which makes it one of the longest running conferences in the field of manufacturing. The conference now runs normally biannually alternating between The University of Manchester, its permanent host and a selected international partner. We are grateful to the visionary Professor S A Tobias and Professor F Koenigsberger who started this series of conferences following the style of the Aachen Colloquium. We are delighted to continue the conference focus, and to broaden MATADOR's reach with the 40th conference held in China for the first time and run very successfully by the Zhenjiang University of Technology. This is evident in the strong regional engagement and paper authorship.

The special issue covers scientific advances in manufacturing processes and systems. Seventy-seven papers were submitted to this special issue, and the published 26 papers reflect the leading research papers that were successful in the journal

Paul Mativenga

P.Mativenga@manchester.ac.uk

1 Department of Mechanical, Aerospace and Civil Engineering, School of Engineering, Faculty of Science and Engineering, The University of Manchester, Manchester M13 9PL, UK peer review process and that captivated the interest of the academic community.

The papers reflect new advances in manufacturing science incorporating for example:

- The increasing, importance, role, and ubiquity of additive manufacturing

- Use of deep learning and machine learning advances to improve manufacturing processes

- Eco-efficiency and sustainability, an increasingly important and pivotal part of the progress to carbon neutral or zero carbon manufacturing and the need to manage the environmental burden of manufacturing

- Pushing the frontiers and capability of manufacturing processes such as advanced machining, laser material processing, welding and electrical discharge machining.

- Hybrid and assisted manufacturing processes and their role in expanding the process capability of manufacture

- Composite materials in manufacture

- Smart materials and their use in 4D printing and to underpin application intelligent structures and actuators.

40th MATADOR Conference Chairmen: Professors Paulo Bartolo, Lin Li, Srichand Hinduja, and Paul Mativenga, The University of Manchester, UK. Professor Jianhua Yao, Zhenjiang University of Technology, China, and Professor Rongshi Xiao, Beijing University of Technology, China.

Publisher's note Springer Nature remains neutral with regard to jurisdictional claims in published maps and institutional affiliations. 